\title{
Ball Bearings from Roman Imperial Ships of Nemilake*
}

\author{
Marco Ceccarelli ${ }^{1}$, Sofia Ceccarelli², Cinzia Elena Conti ${ }^{3}$, Gian Martines ${ }^{3}$ \\ ${ }^{1}$ LARM2 Laboratory of Robot Mechatronics, University of Rome Tor Vergata, Roma, Italy \\ ${ }^{2}$ Department of Industrial Engineering, University of Rome Tor Vergata, Roma, Italy \\ ${ }^{3}$ Ministero dei Beni e delle Attività Culturali e del Turismo, Roma, Italy \\ Email: marco.ceccarelli@uniroma2.it, sofia.ceccarelli@uniroma2.it,cinzia.conti@beniculturali.it, \\ giangiacomo.martines@gmail.com
}

How to cite this paper: Ceccarelli, M., Ceccarelli, S., Conti, C. E., \& Martines, G. (2019). Ball Bearings from Roman Imperial Ships of Nemilake. Advances in Historical Studies, 8, 115-130.

https://doi.org/10.4236/ahs.2019.83009

Received: April 14, 2019

Accepted: June 8, 2019

Published: June 11, 2019

Copyright $\odot 2019$ by author(s) and Scientific Research Publishing Inc. This work is licensed under the Creative Commons Attribution International License (CC BY 4.0).

http://creativecommons.org/licenses/by/4.0/

\begin{abstract}
The remains of ball bearing from the Roman imperial ships of Nemi lake are investigated to understand their mechanical design and to speculate on the machines they were used in. The imperial ships are dated at first century A.D. and they were digged out from the lake with several significant remains in titanic operations in 1930s. Today the bronze remains of the ball bearings can give new insights of the ancient Roman technology with renewed considerations and analysis both from historical and technical viewpoints as per their construction and use.
\end{abstract}

\section{Keywords}

History of Roman Machines, History of Ball Bearings, Reconstruction of Ancient Machines, Performance Evaluation of Ancient Machines

\section{Introduction}

Roman machines attracted and still attract great attention not only for their specific designs of relevant interest for the History of Science and Technology, but also for the surprising level of technology they refer to as technical background for modern developments and even as inspiration sources for modern solutions yet.

From historical viewpoints general considerations are outlined in general stu-

\footnotetext{
${ }^{*}$ A preliminary version of the paper was presented at HMM2018 IFToMM International Symposium on History of Machines and Mechanisms in Beijing, China on 27-28 September 2018 with proceedings published by Springer in the book: Zhang B. and Ceccarelli M. (Eds.), Explorations in the History and Heritage of Machines and Mechanisms-Proceedings of HMM2018, Springer Nature Switzerland AG 2019. https://doi.org/10.1007/978-3-030-03538-9.
} 
dies for the historical timelines to track machine evolution as part of the mankind history as for example in the encyclopedic woks (Capocaccia, 1973; Singer, 2012) and in monographic works like (Galli \& Pisani Sartorio, 2009; Russo \& Russo, 2009; Rossi et al., 2009; Ceccarelli \& De Paolis, 2008). Specific analyses have been also worked out on the machine technology by looking at machines with details on mechanical design and usage, like for example in (Ucelli, 1950; Ghini, 2000; Unknown, 2000).

Nevertheless, there are still aspects to be discovered or better investigated as indicated also in exhibitions of machine reconstructions like in (Russo \& Russo, 2009).

The work in this paper is in the field of refreshing attention to the ball bearing remains in the Roman imperial ships that with a renew investigation can give a new understanding both on the specific archeological remains and the machines they were used in.

The significance of a study on Roman ball bearing remains can be understood not only for the specific historical interest on their designs but even more as an important solution as machine component that today yet in modern machinery indicates the level of technology behind them both from theoretical and practical expertise. Thanks to the proper high-quality ball bearings the Roman engineers could design and operate complex machines successfully as outlined in (Rossi et al., 2009).

This paper discusses results of a recent investigation that has been carried out on the ball bearings belonging to the remains of Roman imperial ships dated back to the first century A.D. during the Caligola'sempire. The ball bearings were discovered together with the finding of two Roman imperial ships in the Nemi's lake, near Rome, during the years 1928-32. The discovery was a result of an impressive recovery work of the ships from the bottom of the lake is reported in great details with first studies on those remains in (Ucelli, 1950). This work brings new light on the understanding of the Roman ball bearings with the results of the renewed investigations on the mechanical design, manufacturing process, and usage in complex machines. However, some aspects still remain unsolved as for alternative speculations in manufacturing and machine implantation as referring to how they were used in the Roman imperial ships since no actions of investigations other that those herein reported were permitted on the archaeological remains.

\section{The Roman Imperial Ships from the Lake of Nemi}

Historical sources and physical evidences have placed the presence of two big Roman imperial ships in the lake of Nemi (about $30 \mathrm{~km}$ south-east from Rome) since the last time of Roman empire. Since always they addressed the attention $f$ and since the beginning of Renaissance they were sources of archaeological investigations, although it is evident that they were sources of findings (permitted and illegal ones) since the first days of their abandon and sink in the first century 
A.D. during the Roma times.

In Figure 1 a pictorial reconstruction is shown as reconstruction for a general public but even for investigators imagining the magnificence of the ships in the Nemilake since they were understood as holy floating temples and emperor summer villa being built for Caligola emperor (12-41 A.D.) very likely in 37-41 AD, (Ucelli, 1950).

The size and rich equipment of the ships addressed attention not only for the artistic aspects of the furniture but even for the technological constructions they were provided of. The artistic findings are today exhibited in several museums, such as Museum of Roman ships in Nemi, (Ghini, 2000), and Museum Massimo of Rome, (Unknown, 2000). Findings contain also technological information when considering their design and manufacturing, such as for examples referring to the several bronze heads and artistic piecesthta were discovered in several campaigns of archeological investigations since $15^{\text {th }}$ century. The first serious attempt to recover the whole ships was made in 1446 by Leon Battista Alberti, who could only well identify the ships and could recover few pieces, (Ucelli, 1950). Later in 1535 Francesco De Marchiworked even with a first underwater suite and he got a better insight of the ships lying on the bottom of the lake at about 10 meters below of the water level. But only in 19th century the interest gave results with the actions of Annesio Fusconi in 1827 and then with the works of Eliseo Borghi with a diver in 1895. Finally, the work of the coronel Vittorio Malfatti during 1895-1908 in several investigations made possible to plan a project for digging out the ship as sponsored by the Italian government with the intervention of several Italian industries, (Ucelli, 1950). The governmental commission with Corrado Ricci as chair worked from 1907 to 1927 to evaluate and elaborate feasible projects for digging out the ships from the lake with cooperation of a team of Italian industries of high technical expertise, such as Costruzioni Meccanica Riva with dr. Guido Ucelli.and Stligerfrom Milan, Societá Elettrica e Gas di Roma e Laziale di Elettricitádi Roma with dr Augusto Biagini, Ditta Lazzarini e Meacci from Rome.

After preparing the buildings, the machines, and a channel for water release by restoring the still-existing Roman one, the operations of pumping out the water of the lake out were started on 20 October 1928, (Ucelli, 1950). They were terminated after several accidents with the planned recover of the second ship lying at about $20 \mathrm{~m}$ below the original water level (the first ship was at $12 \mathrm{~m}$ whereas the maximum deep of the lake is about of $30 \mathrm{~m}$ ) on 8 November 1932. The overall recoveroperation was considered a titanic operation for the time and it addressed surprise and worldwide appreciation with several publications indifferent frames (academic publications and technical reports like the one in (SKF, 1939), and even articles in newspapers and magazines like for example the article Bottazzi, 1928) with a very early information to the public).

The remains of the two digged out ships are shown in Figure 2 by photos of the time. Surrounding the ships several findings were discovered and catalogued 
as to be preserved in Museums. A special museum was built for the two ships on the Nemi lake's shores with a first exhibition to the public on 20 January 1936. Unfortunately, on 31 May 1944 the ships were completely fired by a terroristic action by the German soldiers, (Cinelli, 1944), and today nothing remains of the ships except few parts and metallic elements that are still exhibited in the renewed Museum of Roman ships in Nemi at the lake shores, (Ghini, 2000).

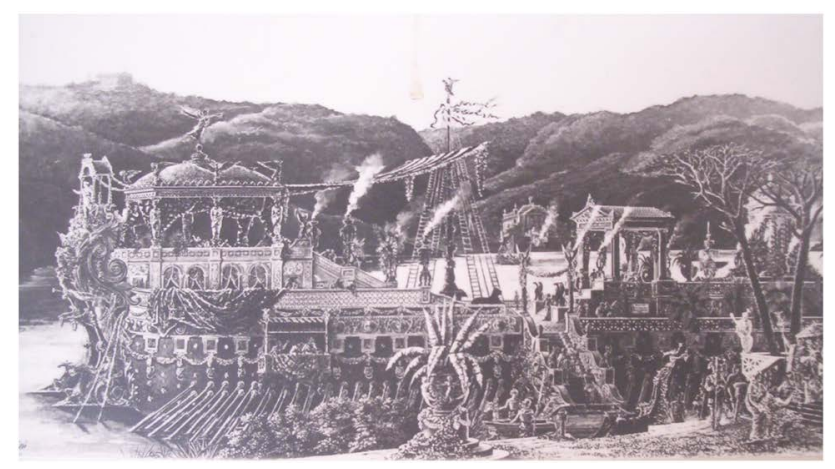

Figure 1. A ship reconstruction from a painting of 1920 s.

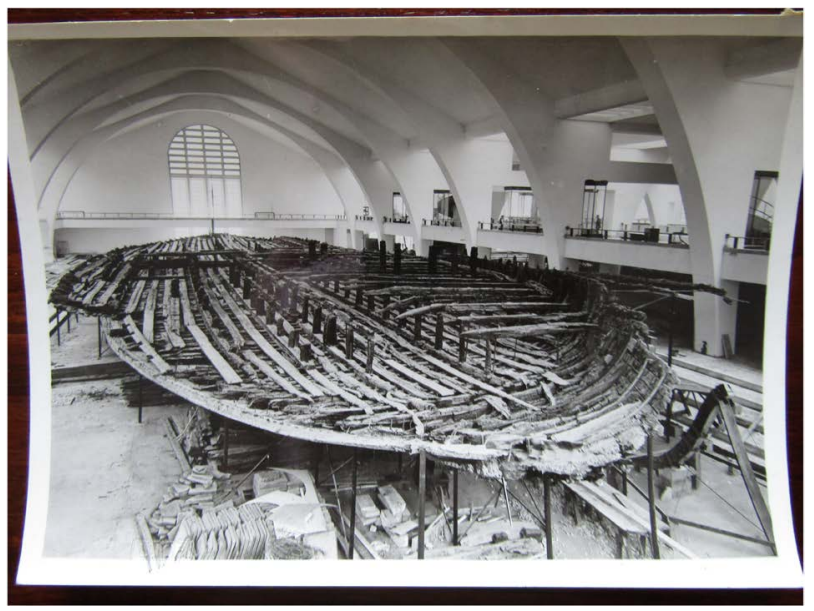

(a)

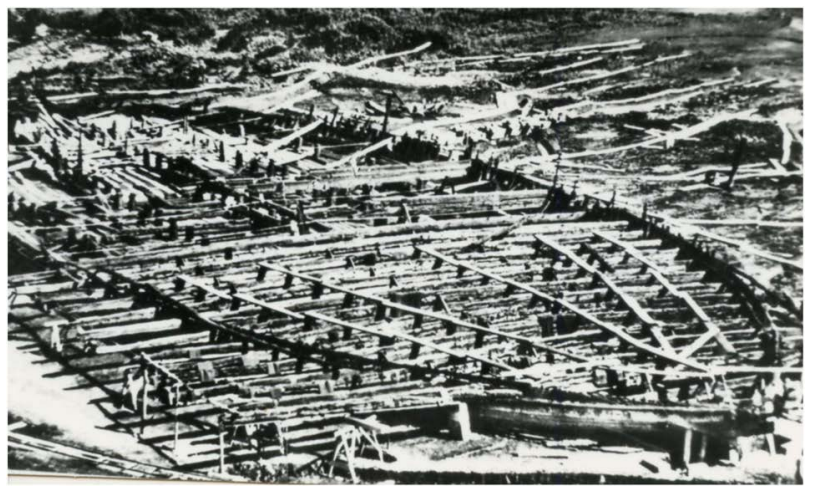

(b)

Figure 2. Remains of the Roman ships asrecovered in 1928-32 from the lake of Nemi: (a) A photo of the 1930s' of the first shipjust stored within the museum; (b) The second ship just digged out. 
The construction of the two ships was and still is considered remarkable both for the sizes $(71.3 \times 20.0 \mathrm{~m}$ and $73.0 \times 29.0 \mathrm{~m})$ and technical solutions for their construction as indicated in (Ucelli, 1950; Bonino, 2003). The structure is made of different high-quality woods with connections that are obtained either by properly shaped wood constraints or iron spikes of high-quality metal. The water insulation was obtained with layers of tar, wool textile, and lead foils that were fixed with large-head copper spikes. The ships should have large over-structures in several floors with rooms with rich furniture and statues even made by bronze as also pointed out in (Ucelli, 1950) and in a recent reconstruction, (Bonino, 2003). It is believed that those rooms were provided even of a heating system like in traditional Roman thermals since specific pipelines whose several fragments were found in the digging out operations and now are preserved in the Museum of Roman ships in Nemi, (Ghini, 2000).

Both ships were provided of big helms with bronze decorations to direct the ship motion. The second ship, as very likely per temple use, was designed with a large area for rovers with the aim to move the ship in the lake. Relevant are also the anchors whose structure was recognized with solutions that were thought of only modern conception. Significant are also the devices that were the equipment for the operation on the ships, such as pumps, norias, valves, small cranes, and winches.

\section{The Rediscover of the Ball Bearings Remains}

Among several impressive pieces, such as water bronze tap and heating water lead pipelines, there are the ball bearings studied in this work as reported in (Ucelli 1950; RIV, 1932) with the exhibition at the time of the discover in Figure 3. The remain sixteen ball bearings are stored in a glass showcase, Figure 4, inside the Nemi's Museum and two of them are still installed on a wood frame, Figure 5. Six of them were found and catalogued by Malfatti in 1895 with codes 33,823 - 33,838 in the National Roman Museum's records. Today, these remains are recorded with code 92 of the new catalogue draft during the operations in 1928-1932, (Ucelli, 1950). The other ball bearings were discovered with the first ship between the end of August and the beginning of September 1929, and they were catalogued with codes 124,831 and 124,832 with the latter referring to the two ones in the wood frame. Since they were found in different places, it is reasonable to think that they were part of different machines. In the reconstruction inside the Nemi's Museum, as proposed at the time of the discover by Ucelli, (Ucelli, 1950), the ball bearings form a circular platform for load rotation (see Figure 8(a)).

\section{Design and Analysis of Ball Bearings Remains}

During the investigation in this report, non-invasive analysis has been carried out for detecting measures, surface status and material information. Due to the random arrangement inside the glass showcase, Figure 4, the identification of 
the single specimen with respect to its mechanical purpose is not possible. The ball bearings are composed of a central spherical body and two extremities with slightly cylindrical/conical pin, as represented in Figure 6 referring to one of them as sample. The main construction dimensions are identified in the diameters and lengths of these parts as modelled in the scheme reported in Figure 6(b) where di $(i=1 \ldots 4)$ are the diameters of the pin extremities, $D$ is the diameter of the spherical body and a, b, L are the lengths of the two pins and the whole ball body, respectively. All the ball bearings are shown in Figure 7 with a numeration given during the analysis in this investigation. The measurements, even the weight, are reported in Table 1. Most of the data agree with the information acquired at the moment of the discovery as in (Ucelli, 1950; RIV, 1932). It is possible to identify the specimen in Table 1 as no. 3, 4, 5, 7, 9, 15 and 16 as the group catalogue with 124,831 code and no. 1 and 2 as the group with code 124,832.

In the remained wood assembly in Figure 8, the ball bearings with numbers 1 and 2 show a 52-degree angle between their axles pointing towards an intersecting point. This configuration may suggest that these ball bearings were part of a circular platform or a circular sector. In the first case, the above assembly gives a radius of about $70 \mathrm{~cm}$ and needs eight ball bearings, as reconstructed by Ucelli, in (Ucelli, 1950). But counting nine bearings as those discovered together below the first ship, a missed should be selected from the others discovered in different places. Or could the circular platform be assembled with eight bearings only? However, considering the 16 specimens as grouped in sets with similar sizes for different applications and/or machines it is remarkable to point out the tolerance characteristics as summarized in Table 2 giving five different sets when the sphere diameter is considered the main parameter of the sets. One can try to combine the sets to find a proper group of 8 bearings with near tolerance but still at least three other groups can be differentiated from each other. It is to note that the pin extremities show slight conical shape whereas very few of them are indeed cylindrical (see no. 3,15 and 16). The wear during the use may have shaped the conical shape as also suggested in (Ferretti et al., 1997).

Remarkable is also that in several ball bearing a small mark can be detected on the head of the pins, as shown in Figure 9, as very probably due to lathe manufacturing.

A CAD model has been elaborated both to recognize the characters of the mechanical design and to simulate the response during operation. The CAD design is designed for a circular platform as in Figure 10(a)) replicating the Ucelli's reconstruction by using the model in Figure 10(b)) for each ball bearing.

A simulation has been computed with a payload of $1000 \mathrm{~N}$ on the platform while the platform rotates at a low speed of $10 \mathrm{deg} / \mathrm{sec}$. The results are computed also in term of stress response of each single ball bearing as shown in Figure 11 where it can be noted that the spherical body does not suffer significant stress as expected as due to the slow revolving motion while the pins show critical conditions at the joints with the spherical body as due to the reaction forces in their functioning as beams under flexion. This can be considered the source of the 


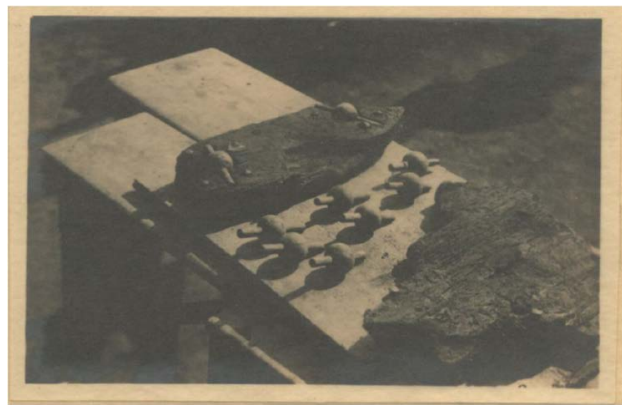

Figure 3. Exhibition of the ball bearings at the time of discover form a video of 1930s'.

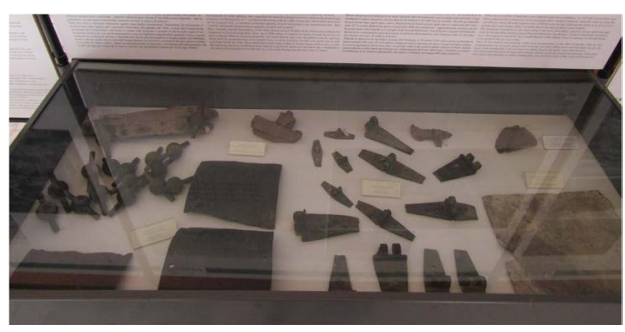

Figure 4. Todays showcase with the ball bearings at the Museum of Roman ships in Nemi.

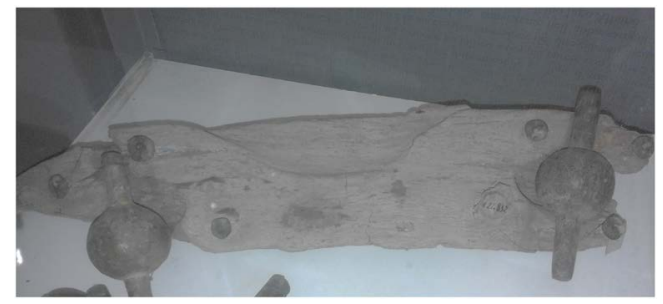

Figure 5. Remains of the wood platform with ball bearings in Figure 4.

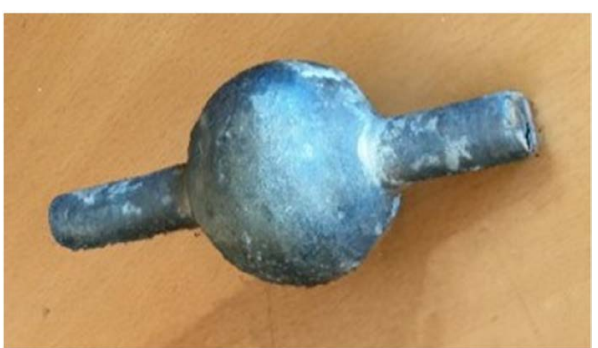

(a)

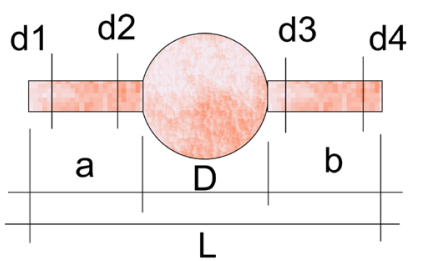

(b)

Figure 6. Sizes of the mechanical design of a ball bearing: (a) A specimen; (b) A model. 


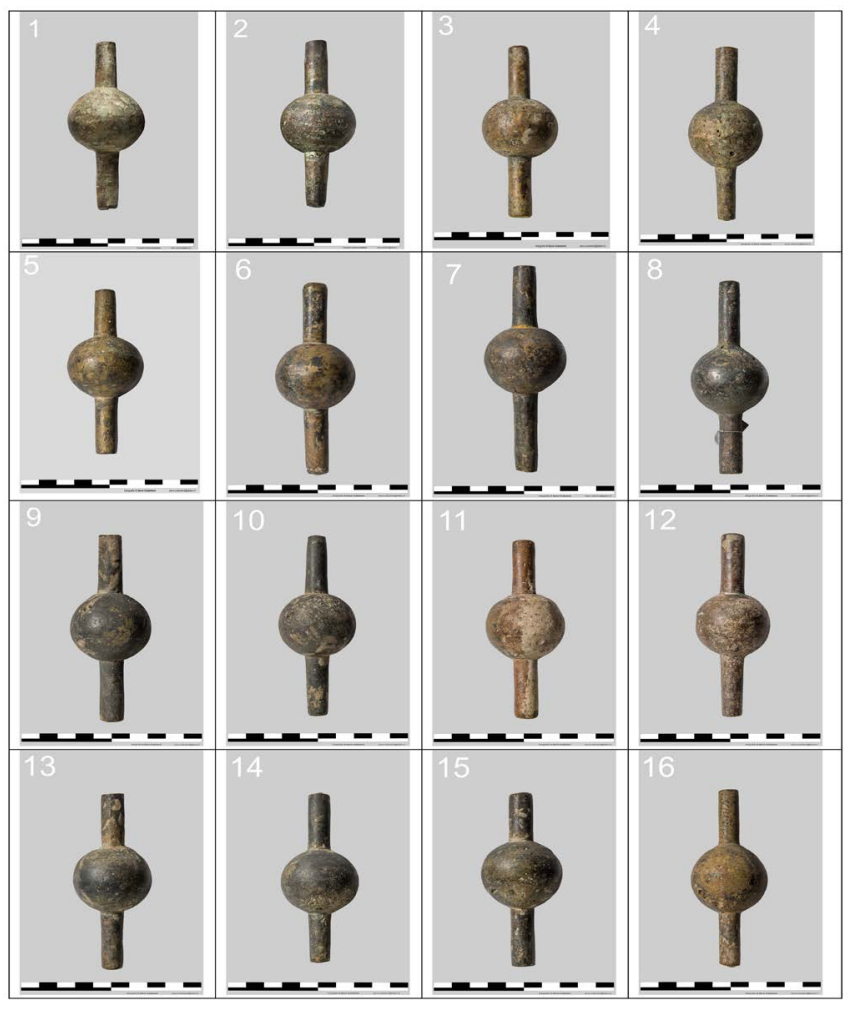

Figure 7. The dicscovered 16 ball bearings of the Roman imperial ships in Nemi lake in Figure 3.

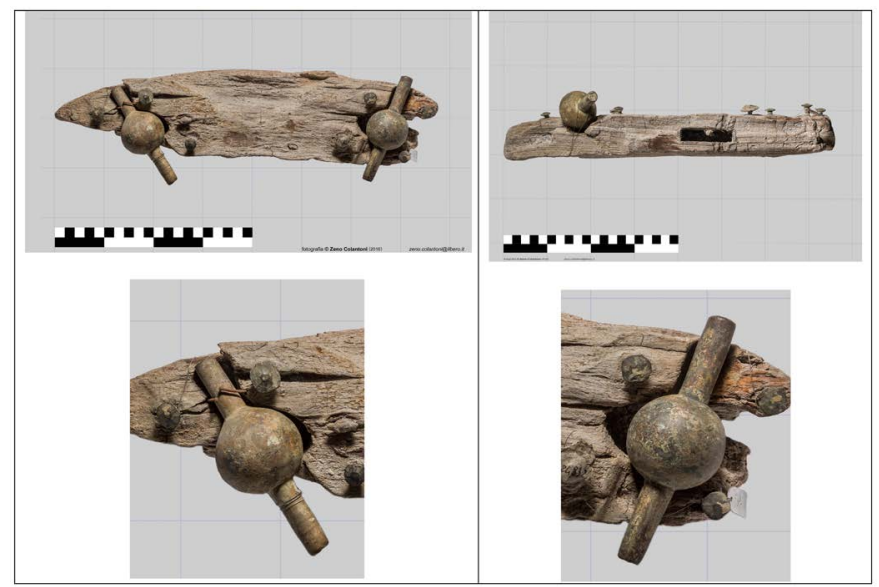

Figure 8. The first two ball bearings in the remained wood frame, Figure 5.

wear that has generated the slight conical shape of the pin extremities not similar in all the ball bearings as pointed out since the discovers in (RIV, 1932). The simulation results emphasize the fact that most of the contact pressure is on the axle and the spherical surface seems to be free form load conditions performing a quasi-free rotation.

\section{Analysis of the Material}

A specific study has been carried out considering the material used in the 


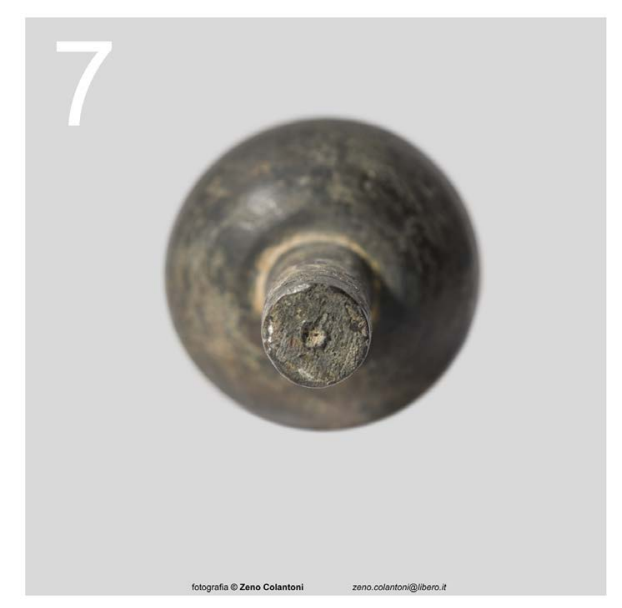

Figure 9. The mark on the head of pin in a ball bearing.

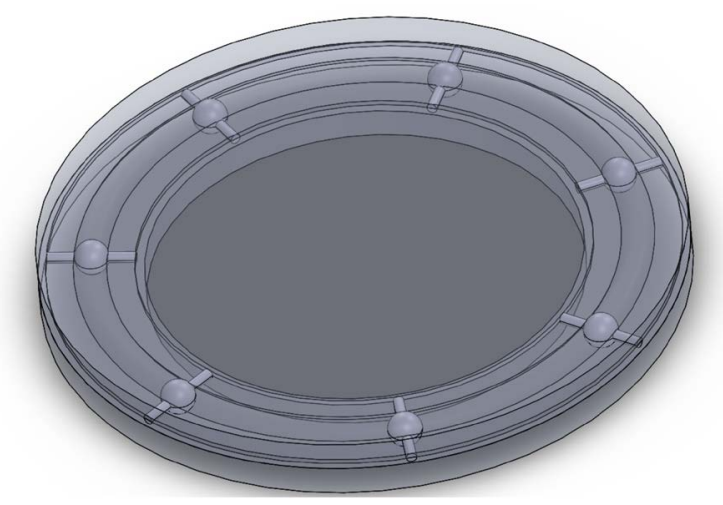

(a)

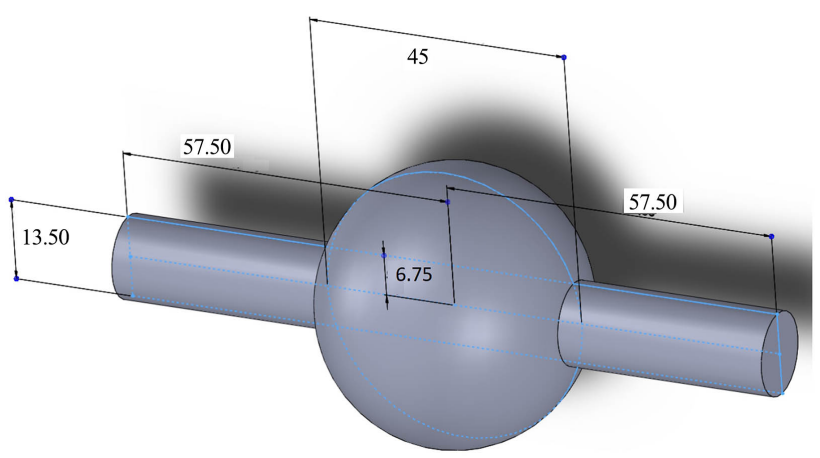

(b)

Figure 10. A CAD model for operation simulation with: (a) Platform design with ball bearings on wood support; (b) A bronze ball bearing Figure 6 .

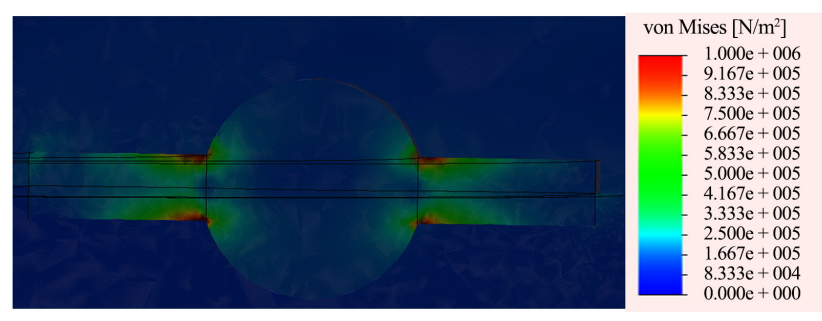

Figure 11. Results of FEM stress analysis of the CAD model in Figure 10. 
Table 1. Dimensional characteristics of the remained ball bearings in Figure 7 as the model in Figure 6(b).

\begin{tabular}{|c|c|c|c|c|c|c|c|c|c|}
\hline No. & $\begin{array}{c}\mathbf{L} \\
{[\mathrm{mm}]}\end{array}$ & $\begin{array}{c}\mathbf{a} \\
{[\mathrm{mm}]}\end{array}$ & $\begin{array}{c}\mathbf{b} \\
{[\mathrm{mm}]}\end{array}$ & $\begin{array}{c}\mathrm{D} \\
{[\mathrm{mm}]}\end{array}$ & $\begin{array}{c}\mathrm{d} \mathbf{1} \\
{[\mathrm{mm}]}\end{array}$ & $\begin{array}{c}\mathrm{d} 2 \\
{[\mathrm{~mm}]}\end{array}$ & $\begin{array}{c}\mathrm{d} 3 \\
{[\mathrm{~mm}]}\end{array}$ & $\begin{array}{c}\mathrm{d} 4 \\
{[\mathrm{~mm}]}\end{array}$ & $\begin{array}{c}\text { weight } \\
{[\mathrm{g}]}\end{array}$ \\
\hline 1 & 112.6 & 35.8 & 36.4 & 42.5 & 11.2 & 13.3 & 13.5 & 13.5 & 423 \\
\hline 2 & 113.0 & 31.8 & 38.5 & 45.8 & 11.8 & 13.0 & 12.5 & 12.5 & na \\
\hline 3 & 114.6 & 35.0 & 38.0 & 45.8 & 13.5 & 12.9 & 13.8 & 13.6 & 455 \\
\hline 4 & 114.3 & 34.5 & 35.5 & 44.7 & 11.0 & 12.5 & 13.5 & 13.3 & 403 \\
\hline 5 & 107.6 & 31.5 & 36.2 & 44.8 & 12.2 & 13.3 & 13.2 & 12.8 & 426 \\
\hline 6 & 120.0 & 41.0 & 36.5 & 45.0 & 12.3 & 14.0 & 13.5 & 14.3 & 465 \\
\hline 7 & 128.2 & 49.0 & 38.0 & 45.0 & 12.5 & 13.6 & 12.4 & 14.1 & 493 \\
\hline 8 & 124.0 & 42.8 & 37.5 & 45.0 & 12.0 & 13.0 & 13.0 & 13.2 & 457 \\
\hline 9 & 115.0 & 36.0 & 37.0 & 45.2 & 13.0 & 14.0 & 13.4 & 13.6 & 462 \\
\hline 10 & 114.5 & 36.2 & 38.0 & 44.1 & 11.0 & 13.0 & 13.4 & 11.7 & 399 \\
\hline 11 & 112.5 & 35.0 & 35.0 & 46.0 & 12.8 & 13.0 & 12.5 & 13.5 & 449 \\
\hline 12 & 115.5 & 38.0 & 36.5 & 43.0 & 12.0 & 13.0 & 13.0 & 14.0 & 433 \\
\hline 13 & 110.5 & 36.0 & 32.0 & 44.2 & 12.6 & 13.2 & 13.2 & 13.0 & 429 \\
\hline 14 & 107.0 & 30.5 & 37.0 & 45.0 & 11.7 & 13.0 & 13.5 & 13.0 & 420 \\
\hline 15 & 109.0 & 30.0 & 36.2 & 46.0 & 13.8 & 13.4 & 14.0 & 14.0 & 461 \\
\hline 16 & 113.2 & 33.5 & 36.0 & 43.3 & 12.0 & 12.0 & 12.0 & 12.3 & 406 \\
\hline
\end{tabular}

Table 2. Tolerance characteristics of the sets from specimen in Table 1.

\begin{tabular}{cccccc}
\hline set & I & II & III & IV & V \\
\hline no. & $1,12,16$ & 10,13 & 4,5 & $6,7,8,9,14$ & $2,3,11,15$ \\
r [mm] & $42.5-43.3$ & $44.1-44.2$ & $44.7-44.8$ & $45.0-45.2$ & $45.8-46.00$ \\
L [mm $]$ & $112.2-115.5$ & $110.5-114.5$ & $107.6-120.0$ & $107.0-128.2$ & $112.5-114.6$ \\
d $[\mathrm{mm}]$ & $11.2-14.0$ & $11.0-14.0$ & $12.2-14.3$ & $12.0-14.3$ & $11.8-14.0$
\end{tabular}

construction of the ball bearing on wood support. At the time of the discover in 1929 they did a chemical analysis (RIV, 1932), that was not possible to repeat since it will require to use part of a specimen. In the report (RIV, 1932) the composition was measured in average with $83.32 \% \mathrm{Cu}, 13.20 \% \mathrm{Sn}, 3.38 \% \mathrm{~Pb}$ and $0.10 \%$ Fe.

Roman copper alloys have been widely investigated with several scientific techniques as in (Moioli \& Seccaroni, 2000; Ferretti et al., 1997; Craddock, 2004; Orazi et al., 2016) from many points of view, among which special attention is addressed to the alloy choice and the casting technique. The relationship be- 
tween the latter elements is deeply linked to the use of the final casted object. For the manufacturing of large and complex structures, such as statues, lead $(\mathrm{Pb})$ was added in order to produce a more fluid molten alloy with a lower melting point, while for military tools zinc $(\mathrm{Zn})$ and lead $(\mathrm{Pb})$ were usually mixed in the copper alloy in order to improve the mechanical resistance. In addition to technological factors, economic, social and symbolic aspects were considered by Roman manufacturer, leading to a complex relationship among alloy, technique and object's purpose, as pointed out for example in (Stan et al., 2017; Dungworth, 2016). The traditional tin (Sn) bronze that is described in Pliny's Naturalis Historia, (Plinius the Old, 1961) has worked with several variations in terms of levels of the principal alloying elements $(\mathrm{Zn}, \mathrm{Sn}$ and $\mathrm{Pb}$ ) but maintaining the coherence between materials and nature of the object being casted. In this work, the single components of the bronze alloy are investigated in order to better understand the casting procedure of the ball bearings belonging to the remains in the Nemi ships. The understanding of the manufacturing of these objects is fundamental for the understanding of their usage inside the mechanisms in the ship. Non-destructive compositional studies were carried out by using the X-Ray Fluorescence (XRF), which analyses the emitted energy in the form of fluorescence X-ray as result of X-rays irradiation. The fluorescence-emitted energy is characteristic of each involved element and its intensity varies according to the quantity of the elements present in the investigated sample (Moioli \& Seccaroni, 2000). The analyses on the ball bearing were performed by the ELIO XG-lab portable system as in Figure 12 with the acquisitions of the parameters that are summarized in Table 3.

The composition examination revealed the presence of copper $(\mathrm{Cu})$ and tin

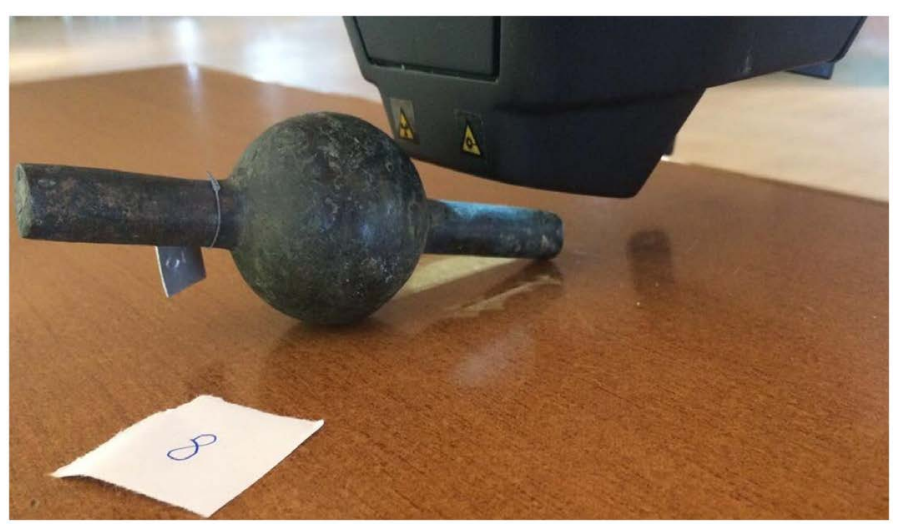

Figure 12. ELIO XRF portable system acquiring fluorescence spectrum from the ball bearing n.8.

Table 3. Acquired parameters by X-Ray Fluorescence (XRF) analysis, Figure 12.

\begin{tabular}{cccc}
\hline $\begin{array}{c}\text { Acquisition } \\
\text { time }\end{array}$ & $\begin{array}{c}\text { Operativity } \\
\text { Energy }\end{array}$ & Current & $\begin{array}{c}\text { Distance } \\
\text { sensor-object }\end{array}$ \\
\hline $60 \mathrm{sec}$ & $40 \mathrm{kV}$ & $80 \mu \mathrm{A}$ & $\sim 1 \mathrm{~cm}$ \\
\hline
\end{tabular}


(Sn) as principal alloy components as expected for a typical roman bronze, while lead $(\mathrm{Pb})$ and iron $(\mathrm{Fe})$ were detected with a minor quantity as being additional elements. The presence of the latter elements in the copper alloy confirms the mechanical purpose of the ball bearing for the characteristics they give in terms of mechanical resistance under motion operation. In addition, the results indicate that the ball bearing bronze is composed of iron, copper, tin and lead, whereas the XRF analysis detected that iron and plumb are non-homogenous distributed in the bodies of ball bearing with differences among the spherical volume and pins.

The above analysis can be considered a further detection of the good value of materials that were used in the ball bearing, in coherence with the high-levels metallurgy of the Romans (Giardino, 2010; Scott, 1991). The use of metals in the ball bearing is according to typical Roman bronze, that was used with different components as function of the object purpose, namely copper and tin are constantly present while lead and iron are less frequent for pottery or utensils, but they are common for statues ormolds (Marabelli, 1991; David et al., 2013).

A final aspect in the analysis has been a check of the surface status of the ball bearings both to look for manufacturing issues and the operation wear. The surface was affected also by the fire of 1944 destroy since in some specimen pieces of carbonate were detected as superficially melted. Nevertheless, it is possible to recognize wear of the spherical bodies due to relatively small rotation about the axle of the pin whereas the pins show both friction-wear together with some remains of the manufacturing due to lathe process, Figure 9. As for friction aspects, the apparent uniform wear in spherical surfaces indicates an application of lubricants. This can be also understood from the wood body frame of the two specimens no. 1 and 2 in Figure 8 since the shape of the spherical frame is a litthe bigger of the spherical body and in communication with a small aside space that could be used for storage and/or feeding of the lubricant.

The above analysis has confirmed some of the aspects of investigations at the time of ship discover in (Ucelli, 1950; RIV, 1932) and has highlighted new remarks and considerations that can be useful for better reconstruction and manufacturing understanding.

\section{Speculations on Manufacturing and Machines Using the Ball Bearing}

Speculations can be elaborated from the above results of investigations and analysis as concerning with the manufacturing and use of the discovered ball bearings in Figure 3 and Figure 7. As for the manufacturing, speculations can refer to the technology of materials and constructions of the discovered ball bearings. The material of the ball bearing is a typical bronze of the Roman imperial time with long tradition, representing high quality as coming mainly from metallurgy casting, (Giardino, 2010; Scott, 1991).

The construction of the ball bearings can be speculated according to two pos- 
sibilities, namely a full fusion in one piece, and two-step manufacturing. A full fusion in one piece could be achieved with a final polishing through lathe works mainly on the axle parts, as identified in some samples in which small marks can be still recognized on the cylindrical surface, and a small pinch is visible on the top surface as for centering purpose on lathe Figure 9,. Even the spherical surface could have been finished with a lathe polishing after the fusion. The one body structure is verified by the results of the XRF analysis that has detected no significant differences in the surface material among the spherical body and pin parts.

The two-step manufacturing hypothesis could be considered as worked out with a fusion of the spherical body on a preliminarily formed axle part. This eventuality can be argued in some samples by looking on the connection areas between the spherical body and the axle cylindrical parts where material is aggregated indicating such a possibility, although it can be considered much more complex and laborious with no particular advantages with respect to the results achievable with the first one technique. The full detection of this manufacturing process could be confirmed by a radiography investigation that is not possible at the moment because of security problem in the museum. However, it is remarkable the good manufacturing that seems not be significantly affected by the wear of an intensive use as it can be recognized in small deformation and signs on the surfaces of both the spherical body and axle parts.

The speculations for the use of the ball bearings give several possibilities of reconstruction. A first one can agree with the Ucelli's proposal as for a circular platform with 8 ball bearings as in Figure 13(a)), that is suggested by the mechanical design and sizes in the small remain of the wood assembly, Figure 8, as reported in (Ucelli, 1950). But this hypothesis cannot fully explain the difference in the discovered sets of the ball bearings as reported in Table 1 and Table 2, and mainly it does not fit with the number of the ball bearings, as previously pointed out. As indicated in the analysis results, the ball bearings can be grouped in four sets with similar geometric tolerance that can indicate their assembly in different units, giving the suggestion of a modular design of those machines using the ball bearings. Still we may recognize the possibility of a circular platform, but something more and different can be speculated as summarized in the scheme in Figure 6 and Figure 13(b)) with modules to be connected for different solutions.

The possibility of use of the ball bearings in linear and curvilinear guides as reported in the scheme of Figure 14 can be recognized by thinking to religious purposes of the ships in which a god or even the god-emperor would have been celebrated in impressive ceremonies by showing heavy statues moving around as carried out on those guides. Actually, a use of similar ball bearings has been recently discovered in archaeological remains of a tower of Neron's imperial house in Rome with the speculated operation of turning the tower with statues or for a kind of observatory above Rome as reported in (David et al., 2013). The reconstruction possibility reported in Figure 14 can be also considered in several con- 
figurations, namely by using parts of it and even as modular assemblies in which the carrier circular platform in Figure 14, replicating the model in Figure 7(a), can be included to provide an additional self-rotation of the carried statue load.

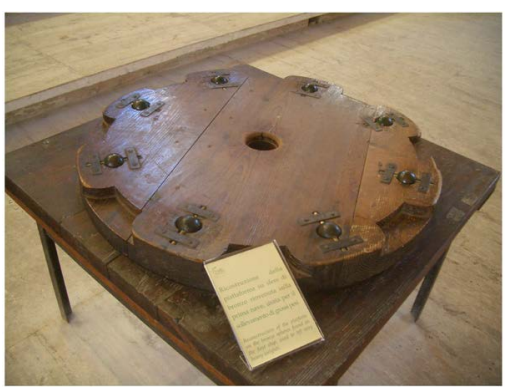

(a)

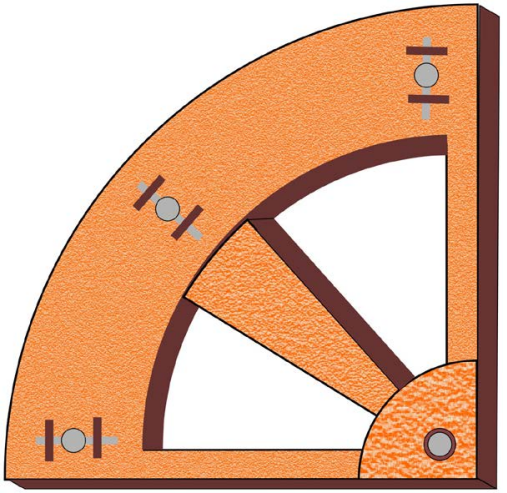

(b)

Figure 13. Speculated reconstruction as circular platform: (a) Ucelli's model in the Museum of Nemi; (b) Authors' CAD model.

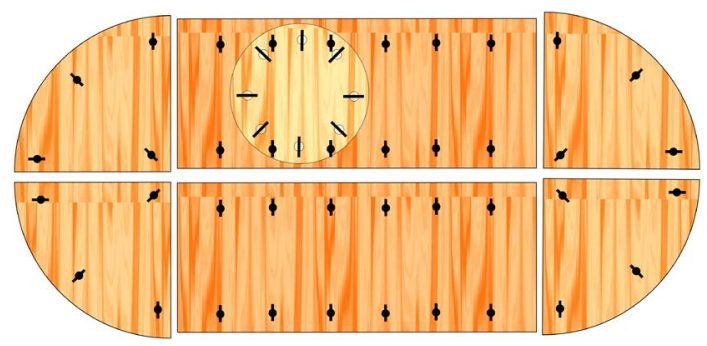

(a)

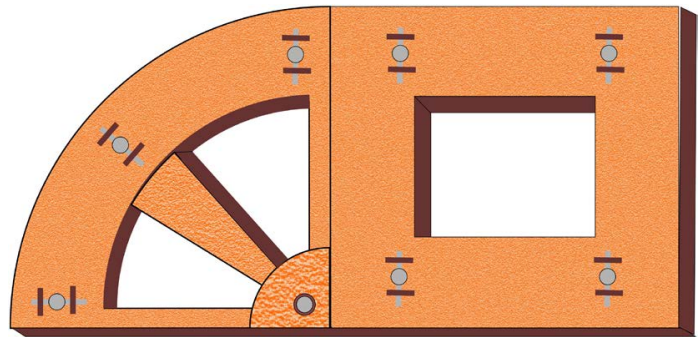

(b)

Figure 14. Anew reconstruction with combined curvilinear long guide carrying a circular platform: (a) A scheme of full assembly; (b) A CAD model of modules for the modular design in (a). 


\section{Conclusion}

This paper presents the results of a renewed investigation on the remains of ball bearing of Roman imperial ships of first century A.D. that were discovered in 1930s from the lake of Nemi (Roma). After a first study at the time of the discover in 1930s, the bronze-made ball bearings in the Museum of Imperial Roman ships at Nemi lake were forgotten and this work brings new light on their significance both for the history and technique of ancient Roman machines. The outcomes of the reported work can be summarized in an identification of a high-level mechanical design with a usage with modern-like characteristics and a speculation of the machine in which they were used as per transportation or movement of high payloads.

\section{Acknowledgements}

The authors wish to thank the Museum of Roman ships in Nemi, the Archive of Rome Soprintendenza at Altemps Palace, the Archive of ItalianNavvy in Rome, for providing archival documents that have been used for the reported analysis work. The photographer Zeno Colantoni is gratefully acknowledged for the professional photos of the bearings that have been used for the analysis investigation. Prof Pier Gabriele Molari of Bologna University is thankfully acknowledged for his collaboration in the studies of this investigation. Prof. Marco Marinelli and his team from Tor Vergata University in Rome are gratefully acknowledged for a material XRF analysis on the ball bearings. The PhD student Matteo Russo is thankfully acknowledged for the computation of the FEM simulations.

\section{Conflicts of Interest}

The authors declare no conflicts of interest regarding the publication of this paper.

\section{References}

Bonino, M. (2003). A Hellenistic Dream: The Ships of Nemi, Felici Editore, Pisa. (In Italian)

Bottazzi, L. (1928). The Roman Ships of Nemi, Corriere della Sera, 31 December 1928. (In Italian)

Capocaccia, A. (1973). History of Technique-From Prehistory to the Year One Thousand. Turin: UTET. (In Italian)

Ceccarelli, M., \& De Paolis, P. (2008). A Brief Account on Roman Machines and Cultural Frames. In Proceedings of HMM2008-The Third IFToMM International Symposium on History of Machines and Mechanisms (pp. 83-100). Dordrecht: Springer. https://doi.org/10.1007/978-1-4020-9485-9_7

Cinelli, G. (1944). Report on the Fire of the Ships of Nemi, Museum of Nemi, Rome, 31 July 1944. (In Italian)

Craddock, P. T. (2004). The Composition of the Copper Alloys Used by the Greek, Etruscan and Roman Civilizations. Journal of Archaeological Science, 5, 1-16. 
https://doi.org/10.1016/0305-4403(78)90015-8

David, L., Fedeli, M., \& Villedieu, F. (2013). The Coenatinrotunda of the Domus Aurea in Vigna Barberini. Archeologia Sotterranea, No. 8, 5-16. (In Italian)

Dungworth, D. (2016). Copper Alloys in Roman Yorkshire. In P. Wilson, \& J. Price (Eds.), Aspects of Industry in Roman Yorkshire and the North (pp. 95-100). Oxford: Oxbow Books.

Ferretti, M., Miazzo, L., \& Moioli, P. (1997). The Application of a Non-Destructive XRF Method to Identify Different Alloys in the Bronze Statue of the Capitoline Horse. Journal of Studies in Conservation, 42, 241-246. https://doi.org/10.2307/1506754

Galli, M., \& Pisani Sartorio, G. (2009). Machina: Technologies of Ancient Rome. Rome: Palombi Editore. (In Italian)

Ghini, G. (2000). Historical Guide of the Museum of Roman Ship of Nemi Lake, Genzano di Roma. (In Italian)

Giardino, C. (2010). Metals in Antique World-Introduction to Archeo-Metallurgy. Roma: Laterza. (In Italian)

Marabelli, M. (1991). The Monument of Marcus Aurelius: Research and Conservation. In Ancient \& Historic Metals: Conservation and Scientific Research (1-19). Los Angeles, CA: The Getty Conservation Institute.

Moioli, P., \& Seccaroni, C. (2000). Analysis of Art Objects Using a Portable X-Ray Fluorescence Spectrometer. X-Ray Spectrometry, 29, 48-52. https://doi.org/10.1002/(SICI)1097-4539(200001/02)29:1<48::AID-XRS404>3.0.CO;2-H

Orazi, N. et al. (2016). Thermographic Analysis of Bronze Sculptures. Studies in Conservation, 61, 236-244. https://doi.org/10.1179/2047058415Y.0000000025

Plinius the Old (1961). Reprint of Naturalis Historia (Book XXXIV, Chapter 20, pp. 95-98).

RIV (1932). Ball Bearings and the Other Mechanical Devices Found with the Ships of Nemi, RIV Report No. 864, Turin, September 1932. (In Italian)

Rossi, C., Russo, F., \& Russo, F. (2009). Ancient Engineers' Inventions-Precursors of the Present. Dordrecht: Springer.

Russo, F., \& Russo, F. (2009). Techne: The Leading Role of the Military Culture in Technological Evolution-Classical Age. Rome: Rivista Militare. (In Italian)

Scott, D. A. (1991). Metallography and Microstructure of Ancient and Historic Metals (No. 77). Los Angeles, CA: The Getty Conservation Institute.

Singer, C. et al. (2012). History of Technology (Vol. 2). Turin: Bollati Boringhieri. (In Italian)

SKF (1939). ETT Kullager Fran Antken. SFAREN, No. 7, 15-17. (In German)

Stan, D. et al. (2017). XRF and Micro-PIXE Studies of Inhomogeneity of Ancient Bronze and Silver Alloys. Nuclear Instruments and Methods in Physics Research Section B: Beam Interactions with Materials and Atoms, 406, 302-308.

https://doi.org/10.1016/j.nimb.2017.02.019

Ucelli, G. (1950). The Ships of Nemi. Roma: Istituto Poligrafico dello Stato. (In Italian)

Unknown (2000). Flyer Guide of the Museum Palazzo Massimoalle Terme, Rome. (In Italian) 